\title{
Artelogie
}

artelogie Recherche sur les arts, le patrimoine et la littérature de l'Amérique latine

8 | 2016

Transgression dans les arts / transgression des arts

\section{Violadores do jogo: Um diálogo entre Artur Barrio e Vilém Flusser}

Debora Pazetto Ferreira et Cleverson Luiz Salvaro

(2) OpenEdition

Journals

Édition électronique

URL : http://journals.openedition.org/artelogie/530

DOI : $10.4000 /$ artelogie. 530

ISSN : 2115-6395

Éditeur

Association ESCAL

Référence électronique

Debora Pazetto Ferreira et Cleverson Luiz Salvaro, «Violadores do jogo: Um diálogo entre Artur Barrio e Vilém Flusser », Artelogie [En ligne], 8| 2016, mis en ligne le 26 janvier 2016, consulté le 02 mai 2019. URL : http://journals.openedition.org/artelogie/530 ; DOI : 10.4000/artelogie.530

Ce document a été généré automatiquement le 2 mai 2019.

Association ESCAL 


\title{
Violadores do jogo: Um diálogo entre Artur Barrio e Vilém Flusser
}

\author{
Debora Pazetto Ferreira et Cleverson Luiz Salvaro
}

1 A filosofia no Brasil não é um assunto muito discutido fora, e geralmente tampouco dentro, dos círculos acadêmicos. Provavelmente porque a tradição filosófica sempre foi predominantemente europeia, ou, mais recentemente, norte-americana, e porque nossa educação acadêmica enfatiza mais o estudo de determinadas questões em determinados autores do que a elaboração de um pensamento próprio. Por esse motivo, pretendemos abordar um dentre os muitos perfis transgressivos da arte brasileira contemporânea com foco na obra 4 dias 4 noites, do artista carioca Artur Barrio - a partir do pensamento de um de nossos filósofos mais originais, e também transgressivo, Vilém Flusser.

2 Flusser, filósofo judeu de origem tcheca, veio ao Brasil no início da década de quarenta, refugiado do regime nazista, viveu mais de trinta anos em São Paulo e escreveu nesse período uma importante - e pouco discutida - parte de sua obra. Naturalizado brasileiro, lecionou Filosofia na Escola Politécnica da USP e assumiu uma cadeira de Ciências da Comunicação na Fundação Armando Álvares Penteado (FAAP). Na década de setenta, a reforma universitária direcionou todos os professores de filosofia da USP ao Departamento de Filosofia da Faculdade de Filosofia, Letras e Ciências Humanas e nosso autor não teve seu contrato renovado, provavelmente devido à falta de comprovação de seus títulos acadêmicos. Não obstante, era extremamente popular como professor e seus alunos costumavam visitá-lo para discutir as mais variadas ideias no terraço de sua casa. Flusser mantinha contato íntimo com as artes e os artistas contemporâneos : publicou diversos ensaios críticos sobre as obras de Mira Schendel, Samson Flexor, Guimarães Rosa, Andy Warhol, Mondrian, Clarice Lispector, Antônio Amaral, Lizzie Calligas, Tsai, Dani Akmen, Solange Zerdoumi, Fred Forest, etc., e conheceu pessoalmente ou manteve correspondências com vários desses artistas. Além disso, escreveu o livro Vampyroteuthis Infernalis em parceria com o artista plástico e cientista Louis Bec e não apenas escreveu alguns ensaios a respeito da Bienal de São Paulo, como participou da comissão instituída para organizar um dos principais núcleos expositivos da $12^{\mathrm{a}}$ Bienal, em 1973. É manifesto que Flusser não era propriamente um filósofo acadêmico - seu pensamento livre e sua 
escrita ensaística cativam os leitores menos pela precisão do que pela vitalidade; qualquer assunto parece digno de suas considerações teóricas, desde a ameba até a menopausa e os toaletes domésticos; e sua filosofia consolidou-se mais nos círculos de conversa com amigos, estudantes, artistas, escritores e cientistas que frequentavam o terraço de sua casa do que nos ambientes institucionalizados da filosofia e da arte.

Embora tenha nascido na Europa, Flusser desembarcou em São Paulo com apenas vinte anos de idade - sua formação como pensador e escritor aconteceu no Brasil. No entanto, tornou-se um autor reconhecido, principalmente como um teórico dos media, apenas depois que voltou para a Europa e publicou, em 1983, A Filosofia da Caixa Preta, na Alemanha. A primeira fase de sua filosofia, desenvolvida e publicada no Brasil, continua sendo muito pouco estudada em comparação com a fase europeia de sua obra. Assim, pretendemos explorar alguns aspectos da constelação de conceitos de Flusser que marcam sua permanência em solo intelectual brasileiro, não apenas por serem menos conhecidos, mas principalmente porque "o pensamento de Vilém Flusser era mais original e transgressor no início de sua produção, isto é, na época da sua atuação no Brasil" (BATLICKOVA, $2004: \mathrm{s} / \mathrm{p})$.

4 A arte, abordada nos mais variados contextos teóricos, sempre foi um assunto fundamental para Flusser. Todavia, o autor não se preocupou necessariamente com a história ou com teorias da arte em sentido estrito, mesmo quando seu objeto de pesquisa era a Bienal ou a obra de determinado artista. Desde seus primeiros escritos, seu foco esteve sempre no ato criativo em geral, que não se restringe ao terreno delimitado como arte a partir da Idade Moderna: o que mais lhe importa é o gesto artístico, o gesto transformador e criador, que pode acontecer em todas as esferas da cultura : na música, na ciência, na economia, na culinária, na filosofia ou no debate político. Se compreendemos a transgressão como um impulso de transformação ou de contestação crítica da realidade, o que Flusser chama propriamente de arte sempre foi e sempre será algo genuinamente transgressor. Em seu primeiro livro publicado, Língua e Realidade, o autor descreve a arte como "poesia" ou "poiesis" - palavra grega que designa a origem de algo, a passagem do não-ser ao ser -, a qual deve ser compreendida como o esforço do intelecto humano para criar novos elementos ou novas informações que possam ser inseridas na realidade. Em outras palavras, arte seria a capacidade de criar, de gerar novas experiências significativas, de fertilizar a cultura com informações, imagens, modelos, experiências e ideias, de inserir na realidade algo que não estava dado de antemão, de buscar elementos fora do roteiro.

\section{Transgressão das experiências e da cultura}

5 Não é necessário que a atividade poiética seja algo assombroso e grandiloquente. Criar pode ser simplesmente vivenciar e fazer vivenciar as coisas de outro modo. Nesse sentido, a ação artística pode ser transgressora ao desenvolver movimentos de "desautomatização" da relação que os sujeitos têm com os objetos, os espaços e com outros sujeitos. Experiências artísticas que transcendem, transfiguram, problematizam ou no mínimo geram um estado de estranhamento aos sujeitos participadores podem reativar os conceitos, os lugares, o tempo e os trajetos relacionados a eles. É nesse registro que se insere grande parte da obra de Artur Barrio.

6 No ato, a princípio simples, de vivenciar a cidade, o artista coloca-se ativamente no último grau de uma experiência deambulatória, conduzindo o próprio corpo a tensões 
extremas em combate direto com as ruas sem nenhum artifício ou abrigo. Sua obra mais radical nessa direção foi o processo 4 dias 4 noites, de 1970, que problematiza a experimentação entre sujeito e cidade - no caso, lugares públicos que não são espaços de passagem, inertes, mas lugares de estadia e de circulação a um só tempo, impregnados e contaminados por essa vivência. Começando no Solar da Fossa, antiga pensão onde morava, reduto da contracultura carioca das décadas de sessenta e setenta, Barrio seguiu caminhando em uma deambulação sem qualquer roteiro, atravessando diversos bairros do Rio de Janeiro ${ }^{1}$, em uma atividade que o levou ao esgotamento físico. Esse desgaste, ao contrário de detê-lo, "abriu uma percepção fantástica, pois com todo esse caminhar a percepção se aguçou incrivelmente" (BARRIO, 2000: 80). Como o título do trabalho sugere, a ação durou quatro dias e quatro noites, e seus relatos, feitos pelo artista, são a única fonte de acesso à obra e aos acontecimentos que a marcaram. Esses relatos são frequentemente vagos e até mesmo contraditórios, fornecendo diversas versões com alguns detalhes que em outras são omitidos, esquecidos ou imaginados.

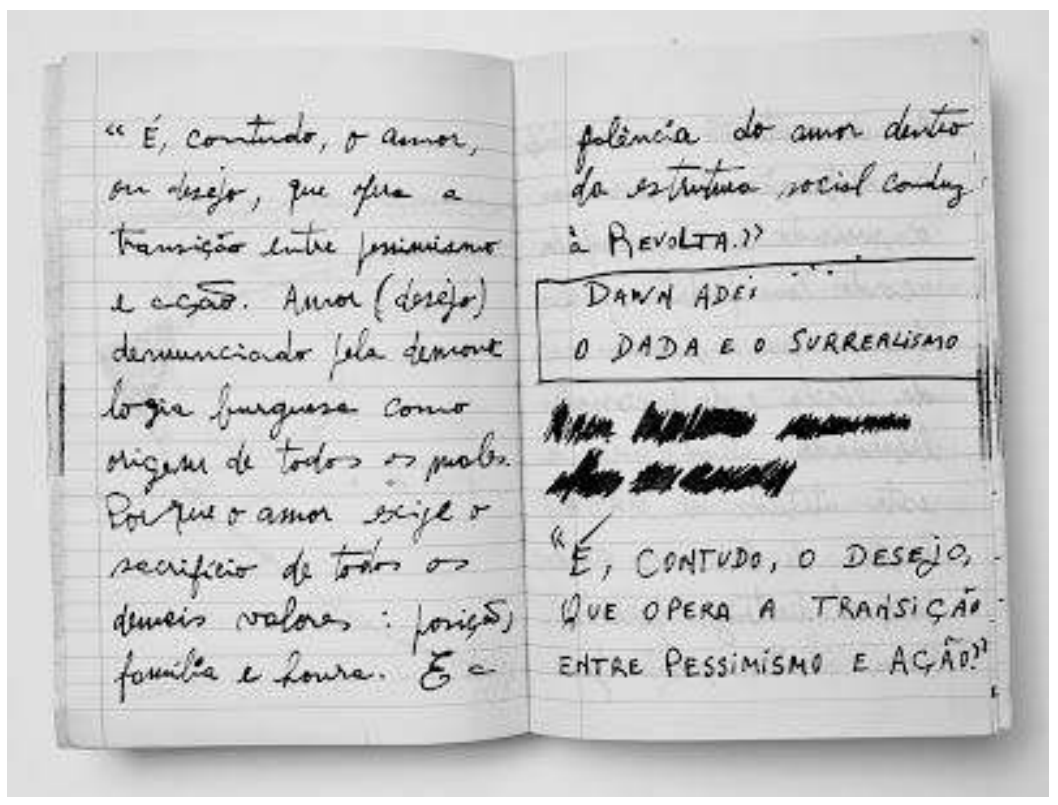

Disponível em: http://arturbarrio-trabalhos.blogsp... Acesso : 10/06/2015

Fotografia: Artur Barrio

7 O que mais evidencia o caráter transgressor dessa ação é que Barrio não produz registros imagéticos de 4 dias 4 noites para mostrar posteriormente em espaços expositivos. Os únicos resultados palpáveis do processo - o qual constitui o trabalho em si, assumido enquanto efêmero e instransponível - foram seus registros nos CadernosLivros, que incluem um texto no qual ele menciona a preparação de um livro contendo quatrocentas páginas em branco, e as várias entrevistas que concedeu a respeito do acontecimento. Dessa maneira, o artista insere explicitamente o valor artístico na própria ação significativa e não fora dela, isto é, em qualquer objeto que poderia ser produzido para venda ou exibição. A obra se concretiza na relação fugidia entre sujeito e lugar, emancipando a arte do peso da produção de resultados. Essa atuação no meio artístico contemporâneo, subversiva em relação ao papel que a arte ocupa na sociedade, é percebida pelo artista em ligação direta com suas concepções a respeito da realidade 
socioeconômica da América Latina². Entre outros fatores, há uma crítica implícita à produção de obras de arte com materiais mais duráveis e/ou mais caros. O deslocamento corporal através de sua própria força motora é transformado no substrato da arte, como um posicionamento contra seu elitismo e uma maneira de "conspirar contra os gostos das classes dominantes - no campo da arte em que estas exercem seu poder cultural e operatório [...], pela utilização de materiais precários e perecíveis, colhidos nos rejeitos de nosso trânsito e fluxo na vida" (COCCHIARALE, 2000: 17).

8 A obra de Barrio é poiética no sentido flusseriano, porque gera a possibilidade de vivenciar a cidade, o espaço, o corpo, o tempo, a relação com outros sujeitos, a marginalidade e o próprio ato de caminhar de um novo modo, de uma maneira que não está no "roteiro prévio" da nossa cultura urbana atual. 0 artista explicita que a ação ordinária de caminhar não se limita à condição física de deslocamento. Esse gesto simples pode conter um posicionamento político, uma experiência de união de corpo e mente, um ato estético, um código de questões não pronunciadas com palavras, mas colocadas em prática. Para Barrio, a constituição corporal da arte refere-se à condição geopolítica do artista: "o confronto do corpo, do fazer, é obviamente uma característica do terceiro mundo por justamente sermos economicamente subdesenvolvidos [...] por isso mesmo o corpo está muito mais presente em qualquer tipo de ação" (BARRIO, $2000: 81$ ).

9 De acordo com o artista carioca, a arte em um país "subdesenvolvido", do "terceiro mundo" revela de diversas maneiras a transgressão como uma espécie de revolta do sujeito diante de sua realidade socioeconômica. Sua obra "tem ligação direta como material e suporte com a teoria desenvolvida por mim (1969) no referente à realidade socioeconômica da América Latina e consequente atuação no meio artístico" (BARRIO, 1978: 35). Essa concepção alinha-se com os principais argumentos de A Arte como Embriaguez - ensaio publicado originalmente na Folha de São Paulo -, no qual Flusser caracteriza a arte, entre os demais entorpecentes, como um modo de esquivar-se de uma vida tornada insuportável pela cultura. $\mathrm{O}$ autor afirma que o homem inventa drogas para escapar da tensão provocada pelas ambivalências da sua cultura: alienação e desalienação, mediação e encobrimento, emancipação e condicionamento. $O$ estado de embriaguez provocado pelos entorpecentes é uma situação de exceção, mas exibe as contorções de toda existência humana, bifurcada entre a necessidade de uma cultura que faz sua mediação com o mundo e com os outros homens, e a alienação que essa cultura pode trazer junto consigo. Flusser afirma que a arte é um estado de embriaguez porque também é um meio para esquivar-se de uma realidade intolerável e violar as instituições que a representam e asseguram. Contudo, trata-se de uma droga especial, porque traduz o esgotamento e a negação da cultura em um objeto, experiência, processo ou pensamento criativos. Ou seja, o gesto inicial do artista é idêntico ao do drogado: revolta-se, procura escapar. Mas diferentemente do drogado, o artista direciona-se para sua cultura ao produzir algo público, que se constitui como questionamento, violação, resistência ou proposta de experimentação diferenciada dessa mesma cultura da qual se origina. Nesse sentido, a arte é um elemento perigoso para os valores culturais estabelecidos, porque experiências novas não funcionam de modo pré-programado - às vezes "algo lhes escapa e passa a agir contra eles" (FLUSSER, 1981: 3) - e isso justifica toda a história da censura à sombra da história da arte. 


\section{Transgressão do objeto e do lugar}

Em Barrio, a subversão da cultura aparece como deambulação, como gesto particular e insurgente do indivíduo que evita a todo custo se integrar às massas e seguir apenas caminhos predeterminados. 0 artista demonstra algumas possibilidades de saída do traçado comum, revela os espaços e as fronteiras que se mantém latentes na geografia urbana. Afinal, os lugares por onde alguém caminha, o espaço que seu corpo ocupa e aquilo que vê são determinantes do seu posicionamento crítico e político na sociedade. Além disso, sua "obra" quase não chega a ser uma obra, e esse é o aspecto mais radical de sua ação, isto é, o lugar que é transgredido acima de todos é o próprio lugar da arte em uma sociedade de consumo economicamente subdesenvolvida. O mundo da arte, o circuito da arte contemporânea, administrado por um mercado que movimenta bilhões de dólares, por instituições culturais públicas, privadas ou mistas, por leis de incentivo à cultura, por críticos, curadores, galeristas, consumidores - esse lugar da arte. Os produtos artísticos que circulam na rede oficial de galerias e exposições têm valores exclusivistas e são completamente consumidos pelos recursos excedentes de uma elite econômica. É um mundo de privilégios, ao mesmo tempo exibidos e barrados, que todos podem ver, mas poucos podem ter. Boa parte da arte obedece à lógica dos investimentos e do fluxo de capitais, e, para que esse sistema funcione, o "produto" é um elemento indispensável. 0 lugar transgredido por Barrio é sobretudo aquele em que a arte é transformada em produto de comercialização. Ainda que seu trabalho seja de alguma maneira assimilado pelas instituições artísticas - de outro modo não o conheceríamos -, ele resiste à materialização, evita tornar-se imagem, nega-se constantemente enquanto coisa palpável para manter a arte no âmbito da experiência efêmera de reorganização espacial da cidade a partir do fluxo não ordenado, imprevisto, imaginado e parcialmente esquecido do artista em seus espaços. 


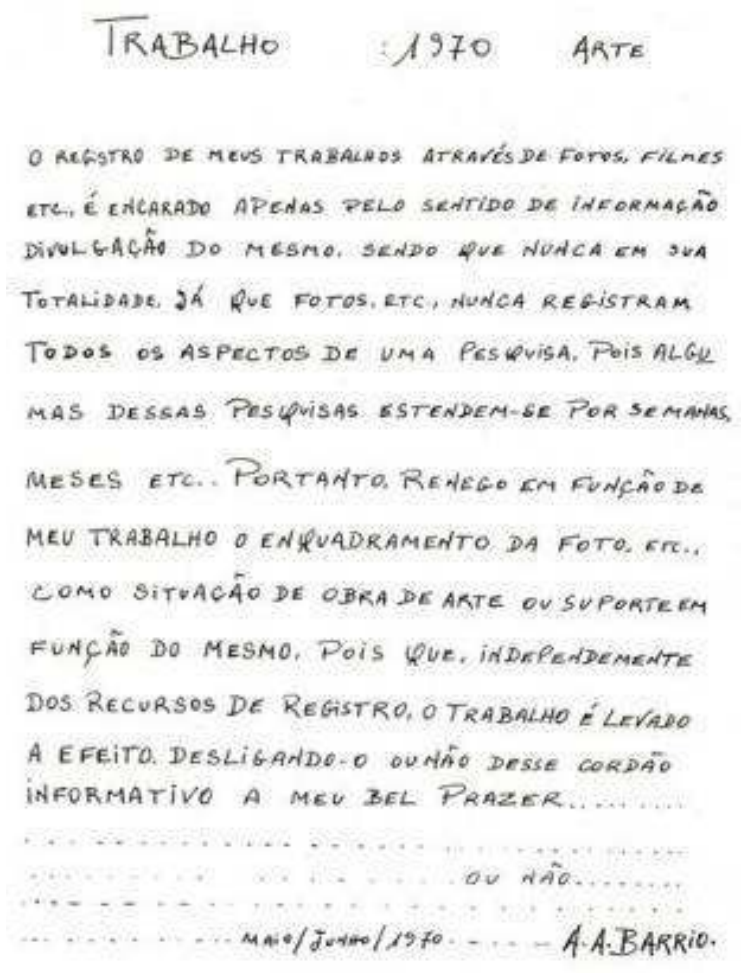

Disponível em: http://arturbarrio-trabalhos.blogsp... Acesso : 10/06/2015

Fotografia: Artur Barrio

11 Naturalmente, o trabalho de Artur Barrio se inscreve no contexto das modificações no campo da arte ocorridas no Brasil desde o início dos anos sessenta, quando os artistas começaram a procurar saídas para a crise da relação com o objeto. Muitas experiências foram vitais para uma ampla mudança de paradigmas que viriam a desestabilizar a preeminência que o "objeto fixo" detinha. Podemos destacar as Anotações sobre o Parangolé, texto no qual Hélio Oiticica discorre longamente sobre a fundamental importância da vivência que o "participador", não mais um espectador passivo, tem ao relacionar-se com a sua obra. Essa participação, para o artista, é algo ativo e não está limitada ao uso de um Parangolé, pois até mesmo assistir essa vivência já influenciaria o público a perceber a totalidade da constituição ambiental (OITICICA, 1986). Desse modo, a fricção causada no contato direto com o porte do objeto seria o auge da experiência, mas a simples disponibilidade do sujeito para participar também abriria sua percepção para a obra. Ainda assim, há passagens em que Oiticica remete seu processo à atitude duchampiana de transmutar um objeto em obra ao declará-lo como tal : "na minha experiência tenho um programa e já iniciei o que chamo de 'apropriações' : acho um 'objeto' ou 'conjunto-objeto' formado de partes ou não, e dele tomo posse como algo que possui para mim um significado qualquer", com isso, a coisa banal transforma-se em obra: "declaro-a obra, dela tomo posse: para mim adquiriu o objeto uma estrutura autônoma - acho nele algo fixo, um significado que quero expor à participação" (OITICICA, 1986 : 77). 
Hélio Oiticica. Parangolé, 1964

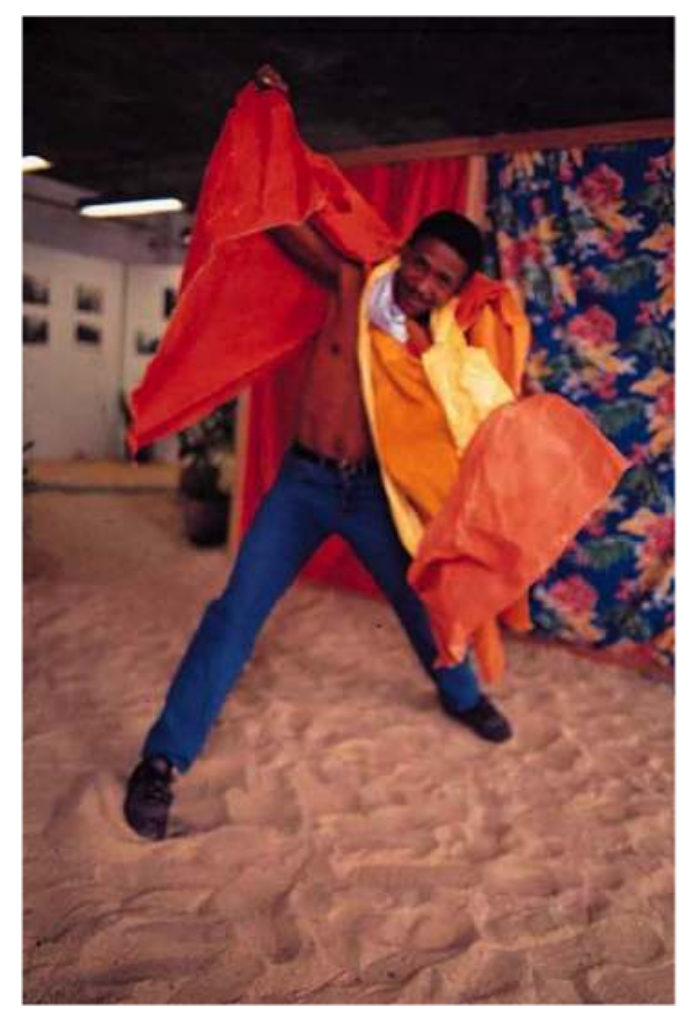

Disponível: http://sabermaisarte.blogspot.com.b... Acesso : 02/06/2015

Na obra de Duchamp, o ato de transformar um objeto não artístico em artístico é mais fundamental do que as características e relações do objeto que é apropriado. Oiticica começa a realizar uma passagem, que se explicita em Barrio, para a apropriação não apenas de objetos, mas de toda a rede de relações e afinidades, de percursos e trajetos, de interações com interlocutores ou participantes, de discursos de sistematização e legitimação característicos do circuito da arte, enfim, da conexão de todos esses fatores e sua interdependência como constitutivos do que podemos chamar de obra de arte. No processo artístico de Barrio, a rejeição da coisa palpável, material, do objeto de desejo, fetichizado pela cultura de consumo, entrelaça-se com a escapada, a pulsão para a errância, os caminhos indefinidos nos quais o artista se perde para, nessa perda, encontrar trajetos sem necessariamente encontrar-se. A experiência artística é precariamente localizada em uma deambulação, atrás de pistas que não foram deixadas com o intuito de serem seguidas, de caminhos que podem revelar situações não imaginadas, inesperadas, de redirecionamentos, de interações fugidias. E o único acesso do público a essa experiência é a palavra do artista, cujo valor pode ser simultaneamente documental e ficcional. o objeto de consumo artístico, o "produto", é radicalmente problematizado.

13 Nesse ponto, mostra-se outro perfil da transgressão, que se apresenta como ato de borrar os limites estabelecidos entre representação ou ficção e realidade. Essa iniciativa é inserida em uma agenda de abolição dos limites entre o artista e o público, entre a obra e o processo, entre a experiência estética e o ato criativo, que são normalmente assegurados pelas convenções dos museus e dos discursos sobre a arte. No caminho da abolição dessas fronteiras, bem como da problematização do objeto artístico, a obra de 
Lygia Clark é igualmente transgressora. Desde seus trabalhos com fitas de Moebius, a artista levanta dúvidas sobre o que está dentro e o que está fora, e sobretudo em Caminhando trata-se do que está dentro e do que está fora da arte. Aos poucos, em trabalhos com objetos relacionais, como Nostalgia do Corpo ou Estruturação do Self, o reino do artístico e o reino do banal são confundidos e geram uma experiência extremamente difícil de categorizar. Porque é preciso dar nomes às coisas, ela acabou chamando-a de "terapia", mas é antes um lugar suspenso que a artista aceita habitar para poder diluir a arte no mundo. Esse é outro modo de violar o lugar da arte em sentido restrito ou acadêmico, e transpor-se para a esfera da experiência significativa da realidade, artisticamente vivenciada. Lygia tentou abolir a distância entre obra de arte e vida, e com isso viu-se na proximidade de transgredir as fronteiras do próprio conceito de arte.

Lygia Clark. Estruturação do Self, 1975

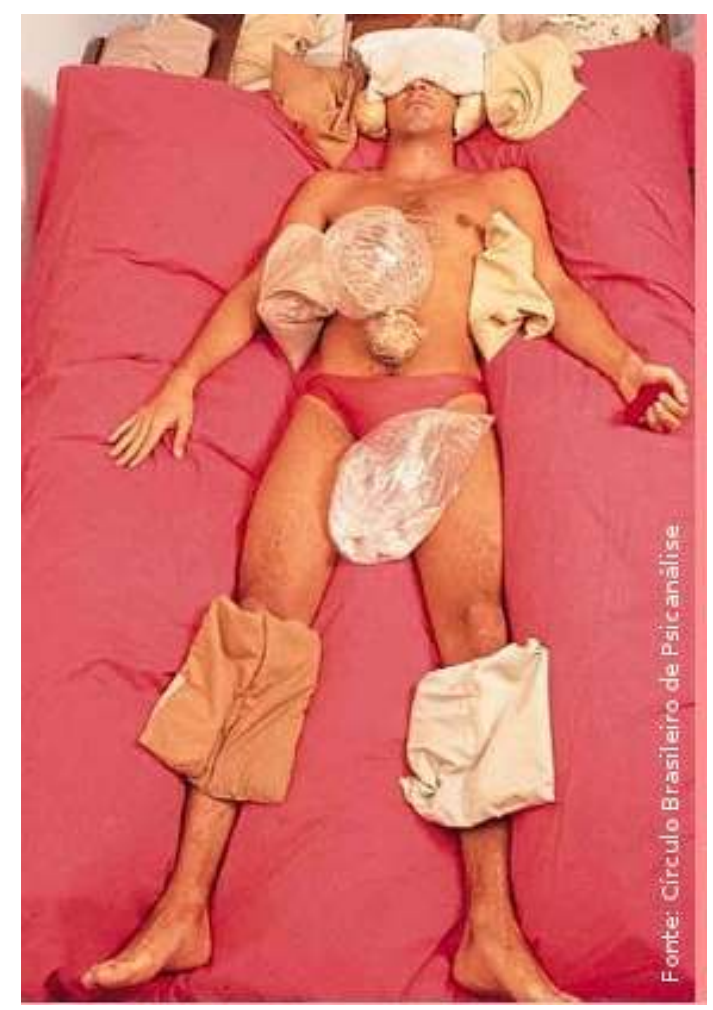

Disponível: http://www.arte.seed.pr.gov.br/modu... Acesso : 02/06/2015

Essa desconstrução do lugar da arte na arte, enfatizada por diversos artistas brasileiros contemporâneos, aponta para a concepção flusseriana de arte como emancipação do homem. De acordo com o autor, o homem poderia, por meio da arte, retomar as rédeas da cultura e estabelecer-se novamente como centro de seus próprios modelos de mundo. Não se trata de um otimismo ingênuo, que supõe que a arte vai salvar a humanidade. Trata-se, antes, de concebê-la como possibilidade de resistir à total automatização do homem pela nossa cultura. Sabemos que a capacidade humana de pensar e agir criativamente, de experimentar o mundo, os espaços, o tempo e as relações com outros sujeitos de uma maneira diferente ou inovadora é algo que está excluído de antemão pela cultura de massas. O novo é censurado, porque a ambição de formatar o público para o consumo e o comportamento programado compromete os produtos, as ideias, os gostos e a sociedade em geral com a repetição de modelos "eficazes". De acordo com Flusser, a arte se 
diferencia da cultura de massas porque instaura novos modelos, propõe novas informações e pensamentos: Artista ou poeta "é aquele que tem (e transmite para dentro da conversação) pensamentos novos" (FLUSSER, 2007: 148). Entretanto, mesmo no circuito da arte, aos poucos o termo "obra de arte" vai sendo substituído pelo termo "produto" e a arte vai se tornando um subconjunto dentro de uma lógica cultural que adota um discurso democrático, mas emprega estratégias hegemônicas de produção, financiamento e divulgação. Processos artísticos como os de Barrio, assim como os de Oiticica e Lygia para citar apenas alguns exemplos -, são transgressores no sentido mais radical: violam a lógica do objeto enquanto produto e caminham sobre a fronteira dos lugares atribuídos à arte.

\section{Transgressão dos territórios e da programação}

Mesmo a noção de fronteira entre espaços é extremamente complexa, pois em cada fragmento desses termos há a implicação de outros mais complicados que indicam diversas direções. "Espaço" aplica-se de maneiras diferentes a um intervalo entre pontos geográficos, temporais ou ainda à determinação de acontecimentos específicos. Constitui uma porção de superfície que agrega pessoas ou expressões sob uma mesma norma. Barrio problematiza o termo ao trabalhar com fronteiras móveis entre espaços, sejam esses ligados à ampla ideia de um conjunto de códigos comuns entre as pessoas, ou imposições normativas de ordem política sobre aspectos psicogeográficos que se oferecem na relação social. A sociabilidade e a experiência vivenciadas em contextos públicos, ainda que experimentadas individualmente, carregam o simbolismo do paradoxo da fronteira, na medida em que não se delimitam facilmente as margens entre o "eu" e o "outro". As práticas sociais compartilhadas no simples ato de caminhar pela cidade vão histórica e continuamente reescrevendo os territórios, principalmente os públicos.

Outra forma de compreender a ação de vagar pela cidade sem mapas ou roteiros é por meio do conceito de desterritorialização, elaborado por Gilles Deleuze e Félix Guattari em Mil platôs. Trata-se de um movimento que pressupõe a linha de fuga de um rizoma, o qual, no caso de Artur Barrio, pode ser compreendido como uma ação rizomática, isto é, uma ação que não segue um caminho ou trajeto único, pré-definido ou linear, mas aponta $\mathrm{e}$ circula por todos os cantos possíveis da cidade, aleatórios e múltiplos. Esse caráter de fuga ou de desvio da desterritorialização desorganiza as linhas segmentadas, que podem ser comparadas às de um mapa da cidade: "todo rizoma compreende linhas de segmentaridade segundo as quais ele é estratificado, territorializado, organizado, significado, atribuído, etc.; mas compreende também linhas de desterritorialização pelas quais ele foge sem parar" (DELEUZE; GUATTARI, 1995 : 18). Os movimentos de desterritorialização e reterritorialização são relativos, ramificados. As deambulações desterritorializam a relação do sujeito com a cidade, com os outros, com o tempo, os trajetos, as fronteiras e os espaços. Por outro lado, a inserção de uma "obra" constituída pela deambulação sem registros imagéticos durantes quatro dias e quatro noites em um espaço institucionalizado de arte reterritorializa essa relação ao transfigurar e ressituar esse procedimento em outro campo, que o legitima enquanto experimento artístico significativo.

17 A malha formada pelas ruas da cidade, que são destinadas cada vez mais ao trânsito rápido e ao deslocamento em veículos, é pouco vivida em seu aspecto profundo como lugar público. 0 território urbano adquire progressivamente um caráter de passagem, de 
algo a ser atravessado e não vivenciado. No entanto, a cidade é o espaço público, o lugar no qual as relações são criadas e estabelecidas; é o lugar praticado, vivido, onde ocorre a experiência do indivíduo (CERTEAU, 1994). São as relações de pertencimento e seus entrecruzamentos que ligam as pessoas aos lugares da cidade, que permeiam as trocas simbólicas e constroem a história e a geografia social. O contato direto, o cotidiano das ruas, que é atualmente associado com a marginalidade, estabelece uma forma de relacionamento com o tecido urbano que busca desautomatizar a relação dos sujeitos com seus espaços de travessia e pertencimento, com o tempo e com as interações possíveis. A deambulação de Barrio é um esforço para pensar e agir de um modo que não seja préprogramado. Vilém Flusser afirma que uma das medidas possíveis da vida é a intensidade das vivências pelas quais passamos. A intensidade, por sua vez, relaciona-se com o inesperado, com a surpresa, com o imprevisível. Ainda que o Brasil seja considerado um país lúdico e a-histórico pelo autor, a cultura Ocidental e ocidentalizada, com seus diversos modos de programar os sujeitos politicamente, economicamente, subjetivamente, afetivamente, ideologicamente, etc., está tornando a vida progressivamente menos intensa: composta de situações previsíveis, programadas, asseguradas (não é por acaso que temos seguros de vida). A saída para essa préprogramação pública e privada que bloqueia a intensidade das vivências encontra-se na experiência artística, "pois a arte é uma atividade que propõe situações imprevisíveis, é um planejamento do não planejado. As propostas que o artista nos faz são propostas para a aventura. Aventura do espírito e dos sentidos, da emoção e do intelecto" (FLUSSER, 71: s/p). E o filósofo conclui: "o território que as artes plásticas atuais abrem é um terreno pra uma possível vida aventurosa, portanto intensa. Com efeito: as artes plásticas abrem um dos poucos terrenos nos quais uma vida intensa é atualmente possível. E nos quais a vida tem sentido" (FLUSSER, 71: s/p). Note-se que esse texto foi publicado originalmente pelo autor no jornal O Estado de São Paulo em janeiro de 1971, ou seja, menos de um ano após as deambulações de Barrio pela cidade do Rio de Janeiro. Ainda que Flusser nunca tenha mencionado o artista carioca em seus escritos, é inegável que as citações acima parecem uma descrição pertinente de seu trabalho.

Outra concepção flusseriana extremamente interessante para pensar a arte contemporânea, e que se aproxima da obra de Barrio, é a de "jogador". o pensador começa a esboçar seu conceito de "jogo" e "jogador" em Fenomenologia do Brasileiro, livro escrito em 1972. $O$ autor argumenta que um jogador pode se posicionar de três modos em um jogo: pode jogar com o objetivo de vencer, ainda que corra constantemente o risco de ser derrotado; pode jogar de modo mais prudente, minimizando tanto os riscos de derrota quanto de vitória ; e pode jogar com o propósito de violar ou subverter as regras do jogo. Essa última modalidade é a única na qual o jogador adquire um distanciamento crítico em relação ao próprio jogo, percebendo-o como algo passível de ser transformado. Em um ensaio intitulado Nosso Jogo, publicado inicialmente no Brasil, em 1983, no livro Pós-História: vinte instantâneos e um modo de usar, Flusser afirma que começamos a usar os “jogos" como modelos para nosso conhecimento e ação social. Por exemplo, não questionamos mais quais são as forças ou os propósitos que movem a sociedade, mas quais estratégias estão em jogo em determinada conjuntura social (FLUSSER, 2011:121, 122). A vida pública, a sociedade e a história tornaram-se matéria prima que pode ser manipulada com tesoura e cola. Essa experiência de manipulabilidade lúdica de estruturas fundamentais aniquila aos poucos nosso senso de realidade, isto é, realidade e ficção são esferas cada vez mais embaralhadas e confundidas. Acreditamos nos telejornais tanto quanto nos filmes de Hollywood. Desse modo, os jogos são nosso novo esquema de 
realidade, somos homo ludens, para usarmos a expressão de Huizinga, somos como jogadores de xadrez que sabem tratar-se de um jogo, mas para quem viver é jogar xadrez. Diante desse jogo geopolítico, sócio-histórico, psicocultural, podemos nos empenhar na vitória, podemos ser peças eficientes, reis ou peões, podemos elaborar estratégias ou então podemos derrubar o tabuleiro. 0 artista é aquele que, a despeito de tudo, continua jogando, mas não para ganhar ou perder e sim para transgredir as regras do jogo.

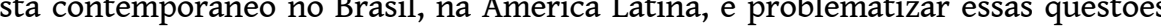
em "um pano de fundo de miséria e carência, remanescentes de tempos ultrapassados mas não superados" (FLUSSER, 71: s/p). Por mais difícil que seja orientar-se nessa conjuntura, a capacidade de perder-se e de vagar sem rumo se apresenta como uma estratégia lúdica que revela a artificialidade do jogo político e social. Flusser também usa essa estratégia em relação à filosofia, isto é, percebe a filosofia acadêmica e seus pré-requisitos de objetividade e cientificismo como um jogo de contenção e aplanamento da potência criativa do pensamento. Por isso, o autor subverte suas regras: sua filosofia, sobretudo na fase brasileira, é lúdica, metafórica, experimental, violadora e transgressora da própria tradição filosófica. No entanto, Flusser foi acolhido como um intelectual de referência na Europa antes sê-lo no Brasil, e, ainda que nos últimos anos seu pensamento venha sendo cada vez mais respeitado por pesquisadores brasileiros, é a fase europeia de sua filosofia que continua em destaque. Atentar para o período em que o autor desenvolveu um pensamento original no contexto do nosso país é relevante não apenas porque impulsiona o escasso estudo da cultura filosófica brasileira, mas, sobretudo, porque oferece um novo ângulo para aprofundar a leitura a respeito de um intelectual tão singular, vasto e criativo.

Diante do esgotamento subjetivo na cultura Ocidental, sobretudo no "terceiro mundo", os artistas e os filósofos contemporâneos precisam ser jogadores do terceiro tipo, isto é, do tipo que desmascara o jogo da própria cultura e propõe aos sujeitos a possibilidade de experiências novas, que não estão em nenhum manual previsível ou programável. As regras que sustentam esse jogo injusto e aparentemente intransponível são sobretudo as técnicas da indústria do entretenimento, as quais são tão complexas que alcançam uma maximização das sensações, em termos quantitativos e não qualitativos, capaz de distrair grande parte da população da consciência e da infelicidade. Para atenuar a capacidade humana de refletir criticamente e de criar novas possibilidades, a indústria da diversão precisa empregar métodos extremos, como o constante bombardeio de sensações - os sons e as luzes ofuscantes nas boates ; a violência ou o melodrama simplório nas salas de cinema ; o sentimentalismo banal nas novelas; a profusão de imagens multicoloridas que estampam pelas ruas alguns símbolos óbvios da felicidade prometida, mas nunca alcançável ; as cores mais vivas e a definição mais precisa do que a própria realidade nas imagens televisionadas; o choque audiovisual das novas tecnologias de imersão, o 3D, os videogames, os gadgets, os milhares de jogos e aplicativos de smartphones. A "sociedade excitada", para usarmos a sagaz expressão de Christoph Türcke, consome sensações e sofre de falta de memória, pois os mesmos clichês estéticos são eternamente repetidos em diferentes formatos. Os produtos são engolidos e eliminados sem serem minimamente digeridos: "não há nem o que deve ser digerido, nem interioridade que possa digeri-lo. Não há intestino nem necessidade de intestino [...]. A sociedade de massas é sociedade de canais que são mais primitivos que os vermes: nos vermes há funções digestivas" (FLUSSER, $2011: 132$ ). processo que vai da mercantilização da arte até sua incorporação ao domínio do comércio 
e da diversão. A transformação da arte em produto de exposição e de consumo é uma maneira de incorporá-la ao jogo socioeconômico da nossa cultura. Todavia, assim como a ação rizomática, os jogos podem se romper, se desterritorializar, se inverter, se ramificar, explodir em linhas de fuga. Encontramo-nos nessa encruzilhada entre a obediência programada e a ação evasiva e negadora: "o espírito do nosso tempo é contraditório, e entre as mandíbulas da contradição está o nosso destino. Artista plástico ou organizador eficiente, jogador ou funcionário público, essas parecem ser as alternativas" (FLUSSER, 71: s/p). Contemporaneamente, o poeta, o artista, o jogador, o pensador são aqueles que de alguma maneira violam o jogo - e nessa transgressão está nossa possibilidade de criar novos significados, novas vivências, novas ideias.

\section{BIBLIOGRAPHIE}

ADORNO T. W., HORKHEIMER M., Dialética do Esclarecimento, Rio de Janeiro, Zahar, 1985.

AUGÉ Marc, Não lugares - Introdução a uma antropologia da supermodernidade, 2 ed. Campinas, São Paulo, Papirus, 2001.

BARRIO Artur, Artur Barrio: A metáfora dos fluxos. 2000/1968, São Paulo, Paço das Artes, 2000.

BARRIO Artur, Barrio, Rio de Janeiro, FUNARTE, 1978. (Arte brasileira contemporânea).

BATLICKOVA Eva, Os elementos pós-modernos na obra brasileira de Vilém Flusser, GHREBH - Revista Brasileira de Ciências da Comunicação e da Cultura e de Teoria da Mídia, nº, São Paulo, Novembro 2004.

BRITO Ronaldo, Análise do circuito, In Crítica de arte no Brasil: temáticas contemporáneas, Glória FERREIRA (Org.), Rio de Janeiro, Funarte, 2006.

CANONGIA Ligia (Org.), Artur Barrio, Rio de Janeiro, Modo, 2002.

CERTEAU Michel de., Invenção do Cotidiano: Artes do fazer, Petrópolis, Vozes, 1994.

Cocchiarale Fernando, "Arte em Trânsito: do Objeto ao Sujeito", in Artur Barrio: A Metáfora dos Fluxos 2000/1968, São Paulo, Paço das Artes, 2000.

DELEUZE Gilles; GUATTARI Félix, Mil platôs - capitalismo e esquizofrenia, São Paulo, Ed. 34, 2007.

oITICICA Hélio, Aspiro ao Grande Labirinto, Rio de Janeiro, Rocco, 1986.

FERREIRA Glória (Org.), Crítica de arte no Brasil: temáticas contemporáneas, Rio de Janeiro, Funarte, 2006.

FLUSSER Vilém; BEC Louis, Vampyroteuthis Infernalis, São Paulo, Annablume, 2011.

FLUSSER V., A arte como Embriaguez, Publicado originalmente em FSP, 06.12.81, folhetim, (255), 12.

FLUSSER V., Pós-História - vinte instantâneos e um modo de usar, São Paulo, Annablume, 2011.

FLUSSER V., Língua e Realidade, Terceira edição, São Paulo, Annablume, 2007.

FLUSSER V., Ficções filosóficas, São Paulo, EDUSP, 1998. 
FLUSSER V., Fenomenologia do Brasileiro, Rio de Janeiro, Eduerj, 1998.

FLUSSER V., Criação científica e artística, Conferência na Maison de la Culture, Chalon s/Saone, 26/3/1982, Disponível no Arquivo Flusser.

FLUSSER V., Habit - the true aesthetic criterium, Manuscrito disponível no Arquivo Flusser, s/d.

FLUSSER V., Da Bienal, Manuscrito disponível no Arquivo Flusser, s/d.

FLUSSER V., A arte como Embriaguez, Publicado originalmente em FSP, 06.12.81, folhetim, (255): 12, 1981.

FLUSSER V., O Espírito do Tempo nas Artes Plásticas, publicado originalmente em SL, OESP, 16 (703) : 4, 03.01.1971.

ROELS JR.; R., SANTOS J. F., "A arte do AI-5 hoje", in Crítica de arte no Brasil: temáticas contemporáneas, Glória FERREIRA (Org.), Rio de Janeiro, Funarte, 2006.

\section{NOTES}

1. É importante salientar que nessa época o Brasil estava sob o regime militar e passava por momentos extremamente complicados após a promulgação do AI-5, em 1968, que dava plenos poderes ao regime ditatorial. Além do completo cerceamento à liberdade intelectual através da censura, o simples ato de perambular pelas ruas podia ser perigoso. Nesse sentido, a obra de Barrio é característica dessa época, na qual realizou-se um 'trabalho de vanguarda, radical, visceral, agressivo e que pretendia colocar por terra não somente as tradições artísticas vigentes - isso já fora feito muitas vezes - mas transformar inteiramente as relações entre a arte e a política. Modificando para isto, se necessário, ambas as coisas' (ROELS JR. ; SANTOS, 2006 : 183).

2. CadernosLivros representam em meu trabalho o embrião do mesmo, pois é lá aonde se encontra quase que em estado bruto o germinar das ideias para consequentes realizações das mesmas. CadernosLivros começou como trabalho em 1966 sendo que o material referente a 66/67/68 e uma parte de 1969 foi utilizado por mim, Barrio, durante a realização do trabalho processo 4 dias 4 noites - maio de 1970 - pelas ruas do Rio de Janeiro, sendo que esse material foi colocado sobre as capotas de alguns carros estacionados em diferentes locais dessa cidade. CadernosLivros têm ligação direta como material e suporte com a teoria desenvolvida por mim (1969) no referente à realidade sócio-econômica da América Latina e consequente atuação no meio artístico. CadernosLivros têm como conteúdo textos / projetos / documentos / trabalhos / reflexões / ensaios / anotações / divagações / contos / ideias / fragmentos de ideias / desenhos / colagens / etc.--------- CadernosLivros têm em si a quase totalidade da documentação referente a meu trabalho. CadernosLivros têm como conteúdo dinamite. CadernosLivros têm como recheio a livre criatividade. CadernosLivros são caóticos. CadernosLivros são um novo suporte. (BARRIO, 1978 : 35).

\section{RÉSUMÉS}

L’article vise à répondre à l'un des nombreux aspects transgressifs de l'art contemporain brésilien. Il se concentre sur le travail 4 jours 4 nuits, conçu par l’artiste Artur Barrio, de Rio de Janeiro, en s'appuyant sur la pensée de l'un de nos philosophes les plus originaux et hétérodoxes, 
Vilém Flusser. Parmi sa constellation de concepts liés à l'art, il y a plusieurs qui peuvent éclairer le travail de Barrio: artiste joueur, proche de la déterritorialisation, transgresseur des expériences. Il permet de questionner la culture comme produit artistique, les espaces établis et les programmes sociaux. Sa performance dans le monde de l'art contemporain est perçue en relation directe avec son point de vue sur la réalité socio-économique de l'Amérique Latine.

O objetivo do artigo é analisar a obra "4 dias 4 noites", do artista luso-carioca Artur Barrio, a partir do pensamento do filósofo Vilém Flusser. Entre a constelação de conceitos flusserianos relacionados à arte, há vários que lançam uma luz sobre a obra de Barrio: artista jogador, desterritorializador, transgressor das experiências e dos lugares, do produto artístico e da cultura, dos espaços estabelecidos e da programação social. A atuação de Barrio no meio artístico contemporâneo, subversiva em relação ao papel que a arte ocupa na sociedade, é percebida em ligação direta com a realidade socioeconômica da América Latina.

\section{INDEX}

Palavras-chave : arte brasileira, filosofia brasileira, Barrio (Artur), Flusser (Vilém), transgressão, deambulação, jogos, Brazil

Mots-clés : art brésilien, philosophie brésilienne, Barrio (Artur), Flusser (Vilém), transgression, déambulation, jeux, Brésil

\section{AUTEURS}

\section{CLEVERSON LUIZ SALVARO}

Debora Pazetto possui graduação em Filosofia e em Artes Plásticas, mestrado e doutorado em Estética e Filosofia da Arte pela Universidade Federal de Minas Gerais. É professora de Filosofia no Centro Federal de Educação Tecnológica de Minas Gerais. Cleverson Salvaro é graduado em Educação Artística pela Faculdade de Artes do Paraná, Mestre em Artes Visuais pela Universidade do Estado de Santa Catarina. Trabalha como artista autônomo, participou de diversas exposições coletivas e individuais. 